\title{
Análise de Discurso Multimodal \\ Sistêmico-Funcional de Livros Didáticos de Jnglês do Ensino Médio da Educação Pública
}

Systemic-Functional Multimodal Discourse Analysis of English Language Coursebooks for High School in Public Education

Reinildes DIAS* Orlando VIAN JR**

Resumo: O livro didático de língua inglesa é uma realidade recente no sistema brasileiro de educação pública. Embora os alunos tenham garantido o direito constitucional de aprender pelo menos uma língua estrangeira na educação básica, o Programa Nacional do Livro Didático (PNLD) passou a distribuir livros de inglês bem recentemente. Como esse material pedagógico é de fundamental importância para o ensino e aprendizagem da língua estrangeria no contexto educacional público, torna-se relevante investigá-lo sob o viés de pesquisas recentes em linguística aplicada. Neste artigo analisamos aspectos multimodais das duas coleções de inglês mais adotadas nas escolas públicas de ensino médio, High Up e Way to Go!, aprovadas pelo PNLD-2015. Adotamos uma perspectiva multimodal sistêmico-funcional para compreender as relações entre as verbiagens e as imagens nestes instrumentos de significação multifacetados e complexos (BUNZEN, 2008). Com base

\footnotetext{
* Doutora em Tecnologia Educacional pela Montreal Concordia University (1998). Mestre em inglês pela UFMG (1985). Estágio pós-doutoral na PUC-SP (2010-2011) e na UNIFESP (2016). Professora Associada da FALE-UFMG.

** Mestre (1997) e Doutor (2002) em Linguística Aplicada e Estudos da Linguagem pela Pontifícia Universidade Católica de São Paulo. Estágio pós-doutoral na PUC-SP (2010) e na Universidade de Sydney, Austrália (2014). Atualmente é Professor Adjunto da Universidade Federal de São Paulo.
} 
em elementos do arcabouço de Painter, Martin e Unsworth (2013), analisamos o corpus a partir de três perspectivas: a integração multimodal, o enquadramento e o foco para entender como os espaços visuais são compostos. Acreditamos que estudos como o relatado neste texto podem ajudar professores de inglês a compreender os aspectos multimodais presentes nos livros com os quais trabalham para que possam aperfeiçoar suas práticas pedagógicas.

Palavras-chave: Análise de Discurso Multimodal Sistêmico-Funcional. Livros didáticos de língua inglesa. Educação pública.

Abstract: Coursebooks for Brazilian public primary and seconday schools for free are still a new reality in the Brazilian context of the English language classes. Although students have the constitutional right to learn a foreign language, the Brazilian Coursebook National Program started distributing English textbooks to all Brazilian secondary public schools only recently. As this pedagogical material becomes of paramount importance for teaching and learning in the public educational context, it is worth investigating it taking into account recent research in applied linguistics. This article analyses the two most adopted coursebooks in Brazilian high schools, High Up and Way to Go!, approved by the 2015 National Program. Our analysis takes a multimodal systemic functional perspective to comprehend the interactions between verbiages and images in these multifaceted and complex instruments of socialization (BUNZEN, 2008). Based on the systemic approach by Painter, Martin e Unsworth (2013), we analysed the corpus from three main perspectives: intermodal integration, framing and focus to understand the ways the visual spaces have been composed. We believe that studies like the one reported in this text can help English language teachers understand the multimodal aspects of the coursebooks they teach with so as to improve their pedagogical practices.

Keywords: Systemic-Functional Multimodal Discourse Analysis. English Language coursebooks. Public Education. 


\section{Introdução}

O livro didático de língua inglesa (doravante LDLI) é uma realidade recente no sistema educacional público brasileiro. Somente no Programa Nacional do Livro Didático (PNLD) de 2012 é que livros didáticos de inglês e de espanhol do Ensino Médio foram incluídos, embora para outras disciplinas do currículo escolar o programa tenha tido início em 1996. O Guia de Livros Didáticos/PNLD 2012 (BRASIL, 2011, p. 7) informa que foram aprovadas, para aquele ano, três coleções de espanhol e sete de inglês, das 32 coleções inscritas, sendo 20 de inglês e doze de espanhol. Mais recentemente, no PNLD 2015 (BRASIL, 2014), duas obras de espanhol e quatro de inglês foram aprovadas, entre elas as duas que são analisadas neste artigo.

Nos Ensinos Fundamental e Médio no Brasil, o LDLI tem papel essencial, pois representa, em muitos casos, uma das únicas formas de contato com a cultura estrangeira e a língua utilizada nos contextos onde se usa o inglês como língua oficial, segunda língua ou língua adicional.

Com o advento do PNLD, muito começou a ser discutido no país sobre o livro didático e seu papel na educação, tendo surgido, inclusive, eventos para discutir os diferentes aspectos envolvidos no seu uso e seu papel no ensino, tais como o Seminário de Pesquisas sobre Livro Didático de Português, tendo sua segunda edição realizada, em 2016, na Universidade Federal do Pernambuco. Conforme explicitado no site do evento (UNIVERSIDADE DE SÃO PAULO, 2012), os objetivos dos seminários são: 1) reunir pesquisadores nacionais que abordam o livro didático de português (LDP) como objeto de investigação; bem como 2) discutir questões epistemológicas e metodológicas das pesquisas atuais (finalizadas ou em andamento), considerando os livros de alfabetização e os de língua portuguesa para os Ensinos Fundamental I, II e Médio. Há, ainda, o Simpósio sobre o Livro Didático de Língua Materna e Língua Estrangeira (SILID) e o Simpósio sobre Materiais e Recursos Didáticos (SIMAR), realizados simultaneamente pela PUC-Rio, cujo objetivo é assim explicitado na página dos simpósios:

aproximar a produção acadêmica, as práticas escolares e o mercado, estreitando relações entre a Universidade, o mercado editorial e as diferentes redes de ensino, e, ao mesmo tempo, estimulando as trocas 
entre os pesquisadores, os agentes envolvidos nos processos de ensinoaprendizagem, elaboração, produção, e divulgação de livros, materiais e recursos didáticos (PUC-Rio, 2015).

É necessário, ainda, mencionar as pesquisas sobre livros didáticos de língua portuguesa (CORACINI, 1999; ROJO; BATISTA, 2003; COSTA VAL; MARCUSCHI, 2005; BUNZEN, 2005, 2008; GUALBERTO, 2016) e outras relacionadas ao livro didático de línguas estrangeiras (DIAS; CRISTOVÃO, 2009; SILVA, 2015; TÍLIO, 2015, XAVIER, 2015; ÁBIO; DIAS, 2016;), que reforçam o papel e a importância desse recurso pedagógico no cenário educacional atual.

Em relação ao LDLI, Predebon (2015) desenvolve estudo com base em duas coleções de LDLI para o Ensino Médio recomendadas pelo PNLD 2012: Prime e English for all. A pesquisa teve como objetivo observar em que medida e como atividades didáticas sobre gêneros dos quadrinhos oferecem potencial para promover o que a autora denomina "letramento multimodal crítico". Xavier (2015), em sua dissertação de mestrado sobre letramento visual crítico, analisa as imagens da coleção High Up, de 2013, “sob o ponto de vista das representações de nuances culturais, étnicas, raciais, sociais e geoespaciais brasileiras" (p. 77), sem, entretanto, se ater à metafunção textual como feito nesta pesquisa. Salbego, Heberle e Balen (2015), por seu turno, investigam como a aprendizagem de inglês pode ser incrementada por meio da análise de imagens em LDLI.

Como resultado dessa realidade, o livro didático passou a ser analisado e debatido. Bunzen (2008), por exemplo, sugere que os livros didáticos de língua portuguesa sejam analisados a partir de uma perspectiva discursiva, como forma de compreender seus diferentes perfis e estilos, e, para tal, o autor sugere que sejam considerados como objetos de investigação complexos e multifacetados.

O LDLI deve, ainda, ser visto como um recurso significativo para o letramento multimodal, pois é por meio dele que o aluno terá contato com a linguagem oral e escrita da língua inglesa, bem como com diferentes recursos multimodais atinentes às culturas de língua inglesa e, para além do elemento linguístico, é necessário uma abordagem para a análise dos elementos multimodais, uma vez que o livro traz recursos semióticos que constroem 
sentidos que devem ser utilizados para o processo de ensino e aprendizagem da língua estrangeira e, desse modo, faz-se necessário o uso de uma abordagem de análise que incorpore as relações entre os elementos linguísticos (verbiagens) e os elementos visuais (imagens).

Para estudo da relação entre as imagens e verbiagens em LDLI, tomamos, neste texto, a proposta de Painter, Martin e Unsworth (2013) para as narrativas em livros infantis e a reconfiguramos para a análise de LDLI, uma vez que, como mostra a experiência no ensino de línguas, o livro didático pode ser considerado como uma fonte para a ADMSF, ou seja, adotamos a proposta de Bunzen (2008) e investigamos o livro como um objeto complexo e multifacetado, e a ampliamos incorporando os princípios da ADMSF.

Por se tratar de um referencial teórico que oferece diferentes possibilidades analíticas, principalmente por ter como foco a (multi)modalidade dos textos sob análise que recai tanto nos elementos linguísticos quanto visuais do livro didático e seu potencial nas práticas de letramento, optamos por focar nossa análise nos significados textuais, para discutirmos como o espaço visual é composto nos LDLI e como se dá a integração intermodal nos livros analisados. Para tanto, este artigo está organizado partindo-se de uma discussão breve sobre a análise de espaços verbo-imagéticos em livros de leitura para crianças, proposta por Painter, Martin e Unsworth (2013), seguida da apresentação do corpus e o nosso estudo sobre algumas das combinações verbiagem/imagem selecionadas por nós a partir dele. Estabelecemos, portanto, algumas relações entre a análise por nós empreendida e os aspectos necessários à formação do professor de inglês para lidar com os livros didáticos multimodais da era atual. Para concluir, apontamos possibilidades de pesquisas futuras que possam contribuir para o enriquecimento e para a produtividade dessa área em nosso país, especialmente na educação básica.

\section{A Análise de Discurso Multimodal Sistêmico-Funcional (ADMSF)}

Com base na análise de imagens proposta por Kress e van Leeuwen nas duas edições da obra Reading Images: A Grammar of Visual Design (1996, 2006), Painter, Martin e Unsworth (2013) a recontextualizam para analisar narrativas visuais em livros infantis, objetivando desenvolver um aparato 
teórico que abarque a relação entre imagem e verbiagem. O argumento central dos autores é que os livros infantis devem ser tomados como uma forma bimodal de texto (PAINTER; MARTIN; UNSWORTH, 2013, p. 2), em que o componente visual tem um importante papel, mas não é único, uma vez que os sentidos são construídos na interface com elementos linguísticos.

Essa proposta, segundo os autores, tem uma importância bastante significativa para educadores atuando com letramento nos anos iniciais da educação, bem como para especialistas em literatura, já que a análise visual não pode caminhar sem a análise linguística na interpretação de tais textos. Os autores argumentam, ainda, que esta é uma contribuição para o campo da Análise do Discurso Multimodal (ADM), principalmente conforme preceituada por O'Halloran (2004) e Jewitt (2009) e tem uma grande contribuição e forte influência da Linguística Sistêmico-Funcional de Halliday (1978, 1985).

É ponto pacífico entre linguistas e analistas do discurso de orientação sistêmico-funcional que mesmo uma robusta análise socialmente e semanticamente orientada com base apenas em elementos linguísticos é apenas uma descrição parcial sobre como os sentidos são criados, já que estes dependem, em grande medida, de elementos visuais, principalmente no atual mundo midiatizado em que textos multimodais circulam com frequência cada vez mais acentuada.

Surge, dessa forma, a Análise de Discurso Multimodal SistêmicoFuncional (ADMSF), que se propõe a proceder à descrição das modalidades postas em circulação num texto multimodal específico. Ou seja, a ADMSF prevê um arcabouço teórico para a compreensão da sinergia entre as diferentes modalidades em um texto a partir das três metafunções da linguagem em Halliday $(1978,1985)$, ideacional, interpessoal e textual, e sua reconfiguração para as imagens em Kress e van Leeuwen (1996, 2006), representacional, interacional, composicional. Para esse fim, Painter, Martin e Unsworth (2013, p. 13) elaboram sistemas de significados ainda não suficientemente desenvolvidos na teoria da ADMSF. São tratados pelos autores os modos como as relações sociais são ativadas (metafunção interpessoal), as representações construídas (metafunção ideacional) e o espaço visual composto (metafunção textual). 
Como já sinalizado, nosso foco de análise recairá sobre a metafunção textual, pois observaremos como o espaço visual é composto nos livros didáticos que compõem o corpus sob análise e, portanto, os sistemas que compõem os sentidos das metafunções interpessoal e ideacional serão apenas mencionados. Remetemos o leitor, no entanto, ao trabalho de Painter, Martin e Unsworth (2013), onde cada metafunção é tratada em um capítulo, para suas realizações nas narrativas infantis analisadas pelos autores.

Para as relações sociais acionadas nas narrativas infantis, Painter, Martin e Unsworth (2013) propõem, com base em Kress e van Leeuwen (2006), os seguintes sistemas: distância social, atitude (que inclui envolvimento e poder), contato e modalidade. Paralelamente ao sistema de distância social em Kress e van Leeuwen, os autores propõem o sistema de proximidade. E paralelamente ao sistema de envolvimento, os autores propõem o sistema de Orientação. Além desses, cinco outros sistemas são propostos pelos autores para dar conta da análise da relação imagem/verbiagem nas narrativas nos livros infantis: Focalização, Afeto, Pathos, Ambiência e Gradação.

Em relação às representações construídas nas narrativas, os autores utilizam as três categorias de construção de sentidos utilizadas em Halliday e retomadas por Kress e van Leuween: Participantes, Processos e Circunstâncias. Tratamos, de modo mais detido, alguns elementos relacionados à metafunção textual e como o espaço visual é composto nos LDLI por meio dos três sistemas tratados nos subitens a seguir: Integração Intermodal, Enquadramento e Foco.

\section{Integração intermodal}

As possibilidades de integração entre as imagens e as verbiagens no layout dos LDLI podem ocorrer de dois modos: no integrado ou no complementar. No integrado a verbiagem aparece como parte da imagem, ao passo que no modo complementar a imagem e a verbiagem aparecem em espaços distintos. Como estamos tratando de uma abordagem sistêmico-funcional, as opções de integração intermodal podem ser organizadas em um sistema, como ilustrado na Figura 1. 


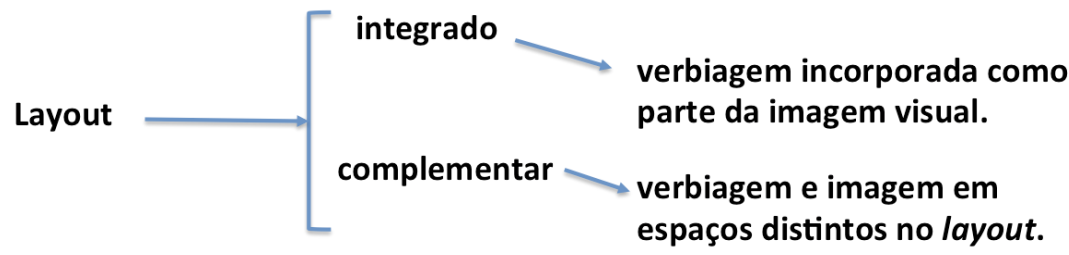

Fonte: Traduzido e adaptado de Painter, Martin e Unsworth (2013, p. 93).

Figura 1 - Opções básicas de integração intermodal

Uma unidade visual integrada pode ser composta pelo uso de dois layouts diferentes, os projetados e os expandidos (PAINTER; MARTIN; UNSWORTH, 2013). A Figura 2 mostra as opções básicas de um layout do tipo projetado. Os exemplos de representações projetadas mais comuns são as tirinhas e as charges, onde imagens (personagens/participantes), sons (balões de fala ou de pensamento) e representações sonoras da linguagem (onomatopeias) encontram-se entrelaçados de tal forma que se torna necessário ler e interpretar a unidade verbo-visual-sonora como um todo no processo de construir o seu significado.

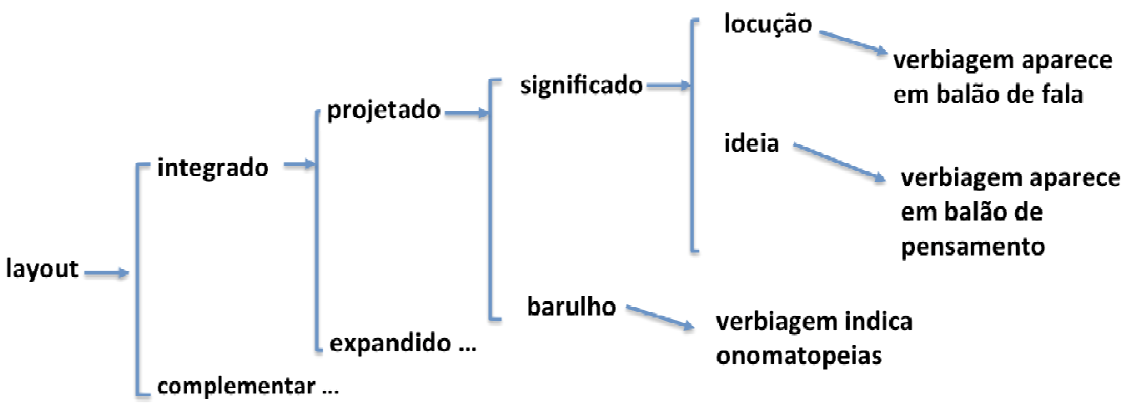

Fonte: Traduzido e adaptado de Painter, Martin e Unsworth (2013, p. 99).

Figura 2 - Opções em um layout integrado-projetado 
Por outro lado, um layout integrado-expandido apresenta diferentes opções de organização do espaço visual, que podem ser vistas na Figura 3. Este tipo de composição pode ser criada de duas maneiras: na modalidade instalada (instated) e na reinstalada (reinstated). A instalada é a mais comum nesse tipo de layout, de acordo com Painter, Martin, Unsworth (2013, p. 100), e, por esta razão, vamos nos ater a este tipo de layout e fornecer alguns detalhes adicionais com base no que os autores preconizam.

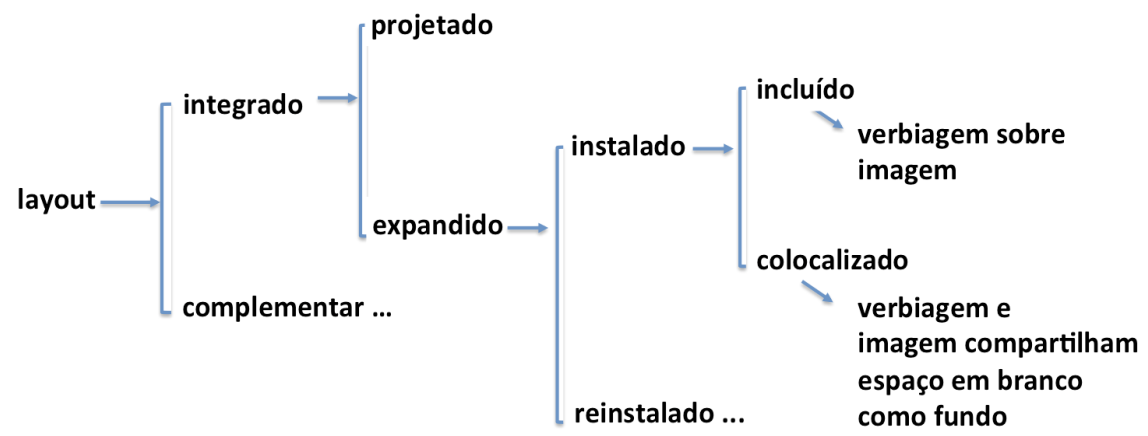

Fonte: Traduzido e adaptado de Painter, Martin e Unsworth (2013, p. 99)

Figura 3 - Opções em um layout integrado-expandido

As composições em um layout expandido instalado-incluído (na opção integrada), por exemplo, criam uma fusão forte entre as palavras e as imagens e, por isso, guiam o leitor para vê-las (e interpretá-las) como uma unidade única de sentido (PAINTER; MARTIN; UNSWORTH, 2013, p. 100). Como exemplos desse tipo de composição verbo-visual, os autores citam esquemas com resumos de informação semelhantes às figuras presentes em nosso artigo, que foram traduzidas a partir das que eles fornecem em seus capítulos.

Diferentemente, nas composições instaladas colocalizadas, palavras e imagens são colocadas umas junto com as outras sobre um mesmo fundo (background), embora possa ser percebido um status um pouco mais proeminente para a verbiagem, como afirmam os autores (2013, p. 100). 
Nos layouts complementares, entretanto, verbiagem e imagem ocupam espaços distintos, mas podem ter relevância e funções diferenciadas quando se leva em conta sua maior ou menor proeminência no espaço verbo-visual que pode ser organizado de maneira horizontal ou vertical (p. 93-95). Na organização horizontal, essas duas semioses podem estar uma de frente para outra ou uma adjacente à outra, e o seu valor no processo interpretativo vai depender do espaço que detêm na página impressa (cf. Figura 4). Se ocupam espaço de tamanho semelhante, não há proeminência de uma sobre a outra e pode-se dizer que ambas são importantes e devem ser igualmente consideradas durante a sua compreensão. Porém, se uma delas ganha relevância por deter mais espaço na página impressa, a mensagem é mais especificamente expressada por meio dela.

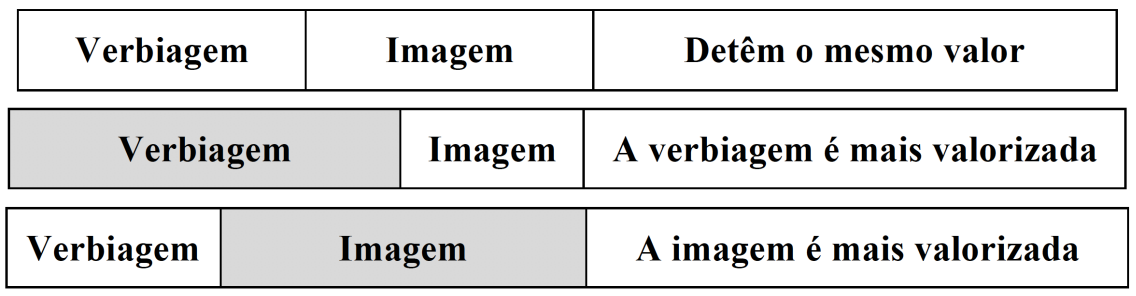

Fonte: Elaborada pelos autores.

Figura 4 - Possibilidades na rede de layouts na organização horizontal

$\mathrm{Na}$ organização vertical, verbiagem e imagem são adjacentes uma à outra, mas uma pode ocupar a parte superior do espaço verbo-visual e a outra alojar-se na parte inferior (cf. Figura 5). Segundo os autores, a semiose que se encontra acima da outra tem uma relevância maior na expressão da mensagem, sendo que, em narrativas infantis, o verbal aparece, com mais frequência, abaixo da imagem. Tal organização é comum também no gênero legendas (captions) que acompanham imagens, pinturas, filmes e vídeos. 

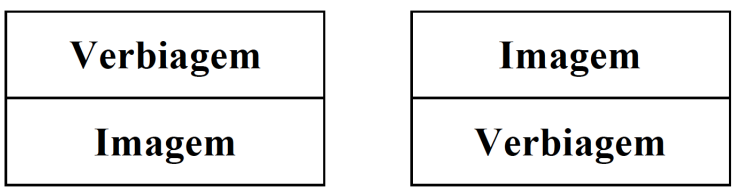

Fonte: Elaborada pelo autores.

Figura 5 - Possibilidades na rede de layouts na organização vertical

Um terceiro arranjo verbo-visual é o chamado sanduíche (PAINTER; MARTIN; UNSWORTH (2013, p. 96), no qual verbiagem e imagem encontram-se de frente para o observador com duas partes verbais interrompidas por uma imagem ou duas imagens "interpoladas" por um componente verbal. Tal organização pode ser disposta tanto na vertical quanto na horizontal (cf. Figura 6). Segundo os autores, a organização vertical ou descendente é mais comum em narrativas infantis, mas ambas as organizações têm por objetivo oportunizar um ritmo adequado para a leitura pelos jovens leitores.

\begin{tabular}{|c|}
\hline Verbiagem \\
\hline Imagem \\
\hline Verbiagem \\
\hline
\end{tabular}

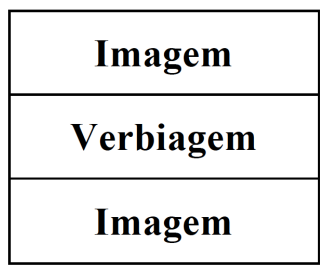

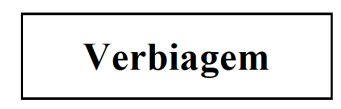

Imagem

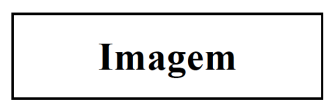

Verbiagem
Verbiagem

Imagem

Fonte: Elaborada pelos autores.

Figura 6 - Possibilidades na rede de layouts na interpolação vertical e na horizontal 


\section{Enquadramento}

Além de considerarmos os modos como as imagens e as verbiagens são organizadas nos layouts dos LDLI, é importante levarmos em conta as possiblidades como se apresentam as imagens nas páginas dos livros e como estas são ou não enquadradas e de que formas tais enquadramentos ocorrem e como se configuram. Vamos observar também quais impactos isso tem na composição da página em si e seu reflexo na unidade e no livro como um todo.

Em linhas gerais, as opções de enquadramento incluem duas possibilidades de enquadramentos, os delimitados (bound) que são aqueles com mais margens, com limites bastante definidos, e os não delimitados (unbound), aqueles com menos margens ou imagens que se expandem pela página ou em páginas duplas.

Foco

O modo como os elementos visuais são dispostos na página para que seja visualizado e apreendido como uma unidade de informação a ser assimilada pelo usuário constituem focos que possuem padrões composicionais e podem caracterizar o LDLI e sua estrutura. Esses grupos focais constituem a informação a ser vista pelo leitor quando olha a página.

Os elementos que compõem o layout de uma página envolvem a disposição dos elementos nela e sua distribuição. Para definição dos elementos do sistema de foco, Painter, Martin e Unsworth (2013, p. 110) basearam-se em estudos acadêmicos das artes plásticas, percepção e fotografia, sendo que as principais escolhas podem ser esquematizadas no seguinte sistema apresentado na Figura 7: 


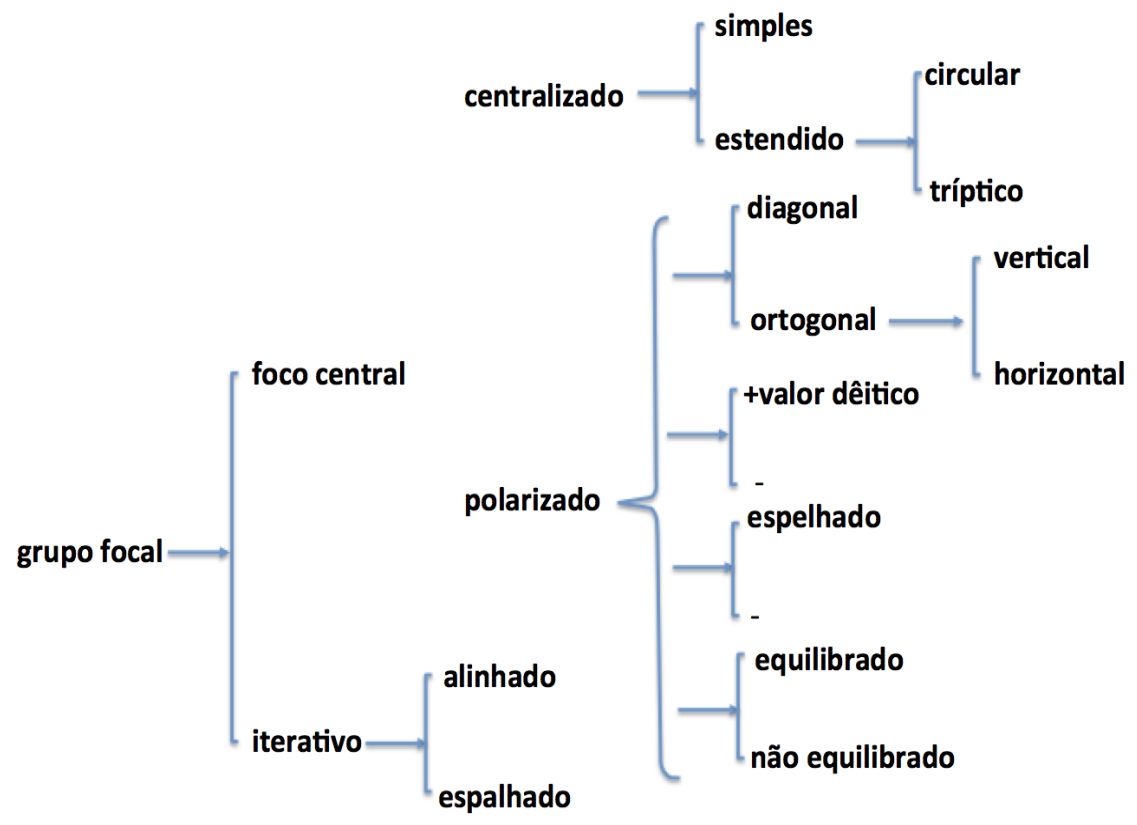

Fonte: Traduzido de Painter, Martin e Unsworth (2013, p. 111).

Figura 7 - Possibilidades na rede de Foco

Desse modo, com base nesses três sistemas de Integração Intermodal, Enquadramento e Foco, observaremos de que modo os dados que compõem o corpus se configuram.

Os Dados e as Unidades de Análise: o LDLI como fonte para a ADMSF

Os dados que compõem o corpus desta pesquisa foram retirados de duas coleções orientadas para o desenvolvimento dos letramentos dos alunos em inglês no Ensino Médio da escola pública. Justificamos a escolha por terem elas sido aprovadas pelo PNLD 2015 (BRASIL, 2014) e serem as duas coleções mais utilizadas pelos professores em todo o Brasil. São elas: High Up (DIAS; JUCÁ; FARIA, 2013) e Way to Go! (TAVARES; FRANCO, 2014), LDLI-01 e LDLI-02, respectivamente, a partir de agora. 
As coleções são formadas por oito unidades temáticas implementadas ao longo de cada um dos três anos do Ensino Médio. Ambas possuem seções exclusivas para atividades extraclasse de consolidação da aprendizagem de gramática e vocabulário, glossários bilíngues, listas dos verbos irregulares e sugestões de livros e sites para os alunos. As duas contêm um CD de áudio para as atividades de compreensão oral e disponibilizam objetos educacionais digitais para os alunos que são complementares ao material impresso.

Elas divergem em alguns pontos: a coleção LDLI-01 oferece questões originais semelhantes às do ENEM para o preparo dos alunos, tendo em vista este exame; a LDLI-02 inicia seus volumes com Tips for Practice que incluem orientações breves sobre estratégias de leitura aplicadas a textos de vários gêneros. A primeira contém quatro atividades de produção textual, ao longo de cada um dos volumes, sempre após as unidades pares. A outra, porém, inclui atividades desse tipo em todas as suas unidades. O LDLI-01 faz um uso levemente mais expressivo de componentes imagéticos nas páginas de abertura e inter-relaciona verbiagens e imagens com um pouco mais de consistência ao longo das unidades dos três volumes. Segundo a avaliação do PNLD 2012, o manual do professor esclarece os objetivos principais dessas obras destas maneiras:

Seu objetivo principal é desenvolver o letramento dos alunos para o uso do idioma inglês em práticas sociais de comunicação na modalidade oral, na produção escrita e na leitura, nos meios digitais e impressos (LDI-01, p. 2).

pretende ser um instrumento no processo de ensino-aprendizagem da língua inglesa [a fim de] contribuir para o desenvolvimento da formação dos alunos como indivíduos que utilizam a linguagem, de forma crítica, em diversas práticas sociais (LDI-02, p. 179).

Cada unidade das duas obras é subdividida em seções, como mostra a Figura 8. Para efeitos da nossa análise, procederemos a um recorte das obras, enfocando as seções listadas a seguir e destacadas em negrito na mesma Figura 8: 
Warm up: páginas de abertura que contêm os objetivos da unidade. Have your say - Before reading (seção de pré-leitura)

Reading beyond the words - Reading (seções de leitura e pós-leitura).

Put it in writing - Writing (a seção de produção textual).

\begin{tabular}{|c|c|}
\hline LDLI-01 & LDLI-02 \\
\hline Warm up & Warm up \\
\hline Have your say & Before reading \\
\hline Reading beyond the words & Reading \\
\hline Genre Analysis & - Reading for general \\
\hline Vocabulary & comprehension \\
\hline Grammar & - Reading for detailed \\
\hline In other words & comprehension \\
\hline Practice makes perfect & - $\quad$ Reading for critical thinking \\
\hline & Vocabulary Study \\
\hline The way it sounds & Language in use \\
\hline $\begin{array}{l}\text { Put it in writing way it sounds } \\
\text { Put }\end{array}$ & Listening and speaking \\
\hline Talk Active & Writing \\
\hline Self Assessment & Your learning (a cada duas unidades) \\
\hline Going Beyond & Looking ahead \\
\hline
\end{tabular}

Fonte: Materiais didáticos analisados.

Figura 8 - Seções das unidades do LDLI-01 e do LDLI-02

\section{Análise do Espaço Visual em Unidades de Duas Coleções de LDLI}

Nossa análise tem como foco o espaço verbo-visual dos dois livros didáticos de inglês, LDLI-01 e LDLI-02, tendo em vista o modelo de Painter, Martin e Unsworth (2013), e encontra-se subdividida em três partes. $\mathrm{Na}$ primeira, vamos discutir a integração intermodal no layout das duas coleções, privilegiando os dois tipos, o integrado e o complementar, e seus subcomponentes; em seguida, analisaremos o enquadramento em suas duas ocorrências, o delimitado e o não delimitado; e, por último, vamos discutir se o grupo focal dos elementos composicionais encontra-se exclusivamente na verbiagem ou na imagem ou na combinação dos dois. 
O layout integrado projetado, nas opções significado e barulho (Figuras 9 e 10), está presente, nas duas coleções, nos gêneros tirinhas, utilizados especialmente para as atividades de compreensão escrita em ambas as obras.
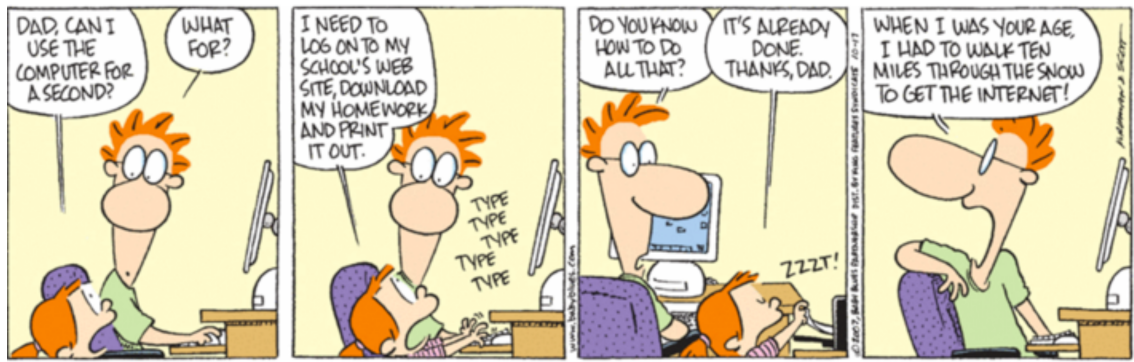

Fonte: LDLI-01, v. 1, p. 128.

Figura 9 - Tirinha LDLI-01 ${ }^{1}$
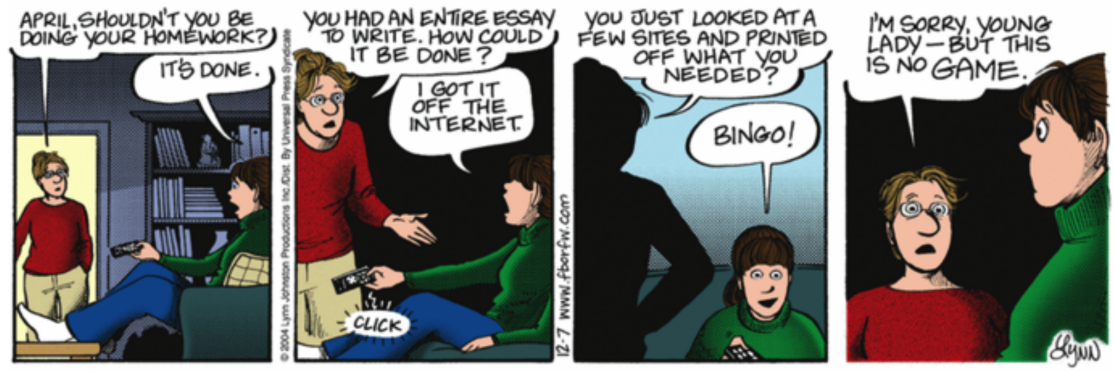

Fonte: LDLI-02, v. 1, p. 21.

Figura 10 - Tirinha LDLI-02

${ }^{1}$ No livro didático, os painéis estão em sequência diferente do original para que os alunos os identifiquem, com base no uso do seu conhecimento anterior sobre o gênero e nas estratégias de leitura. 
Acreditamos que, por ser o LDLI-01 mais estreitamente fundamentado em uma abordagem de ensino por meio dos gêneros, ele traz estudos de análise e consolidação de conhecimento sobre o layout integrado projetado, especialmente na unidade 7 do volume 1 , na página 131. As atividades 4 e 5 dessa página têm por objetivo o estudo, a aprendizagem e a apropriação das características deste tipo de layout pelos alunos (Figuras 11a e 11b).

4 Look at the bubbles below. Match the circled resources used in the comic strips to their meanings.
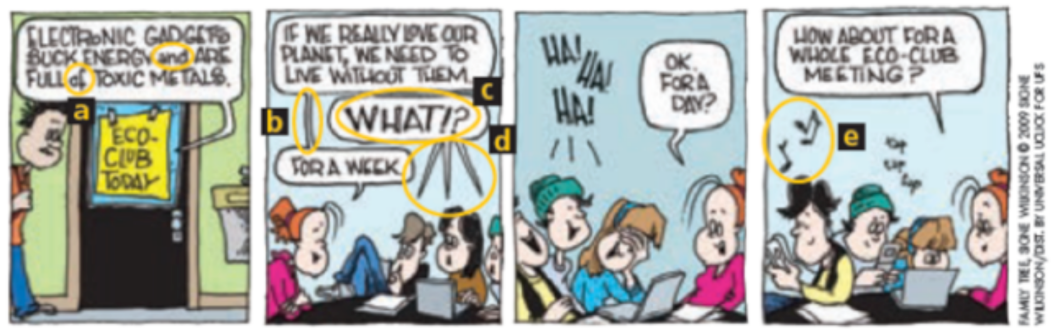

d same sentence, different speakers

a no emphasis

c. emphasis

b same speaker

[e music

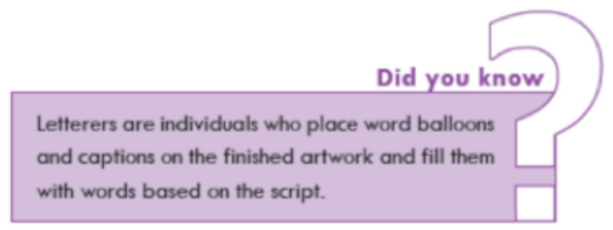

Fonte: LDLI-01, v. 1, p. 131.

Figura 11a - Atividades sobre o gênero tirinha 
Look at the different speech bubbles and complete the sentences below.

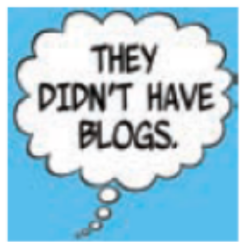

thought bubbles

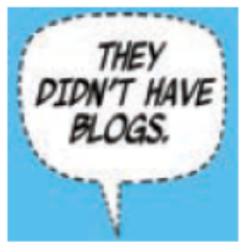

whispering bubbles

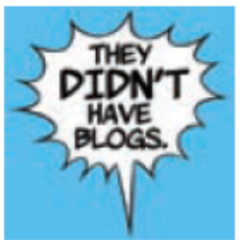

burst bubbles

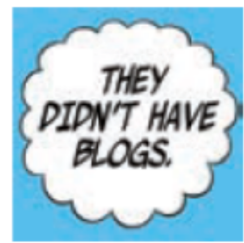

telepathic bubbles

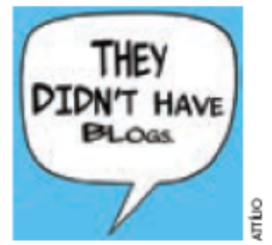

weak bubbles a

Whispering bubbles are used when a conversation is spoken in a low voice.

h

$$
\text { c }
$$
d e Weak bubbles are used when someone is shouting. indicate that the character is speaking telepathically. show what the character is thinking. indicate that the character is feeling weak, maybe sick.

Fonte: LDLI-01, v. 1, p. 131.

Figura 11b - Atividades sobre o gênero tirinha

O layout expandido, instalado, colocalizado, por sua vez, está presente na composição de muitos dos textos retirados de fontes diferentes (como revistas, livros impressos, blogs, páginas da web etc.). Tais textos, de diferentes gêneros, servem de apoio às atividades de aprendizagem que são produzidas pelos autores dos dois LDLI discutidos neste artigo. Nessas composições, a imagem e a verbiagem integram-se em um arranjo unificado, tendo como fundo uma cor sólida ou o branco, com um leve destaque para a verbiagem. Exemplos de tais arranjos verbo-visuais são os infográficos, mostrados nas Figuras 12 e 13, retirados de sites diferentes, utilizados por LDLI-01 e por LDLI-02 nos volumes para o primeiro ano. Com base neles, há atividades 
de compreensão escrita, produzidas pelos autores das coleções, sobre as opiniões de avaliadores críticos diferentes relativas ao filme The Amazing Spider-Man, no LDLI-01, e sobre as informações mostradas e visualizadas sobre as línguas mais utilizadas na web, no LDLI-02.

Tendo em vista a diagramação das duas coleções pelas suas respectivas equipes editoriais, os títulos das unidades e os das diferentes seções são compostos por verbiagens sobre cores diferentes para enfatizar o espaço verbo-visual de cada um deles, o que evidencia o uso do layout expandido, nas opções instalado e incluído. Alguns exemplos, retirados dos dois LDLI sob nossa análise, podem ser vistos nas Figuras 14 e 15.

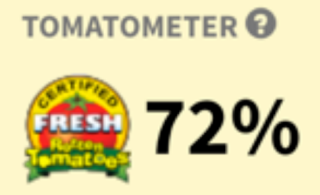

Average Rating: 6.7/10

Reviews Counted: 304

Fresh: 221

Rotten: 83
All Critics | Top Critics

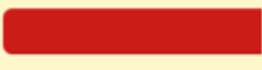

Critics Consensus: A wellchosen cast and sure-handed direction allow The Amazing Spider-Man to thrill, despite revisiting many of the same plot points from 2002's SpiderMan.

Fonte: LDLI-01, v. 1, p. 54.

Figura 12 - Infográfico sobre o filme The Amazing Spider-Man 


\section{ENGLISH THE WORLD LANGUAGE}

\section{Speakers of English as a} percentage of world population* ?

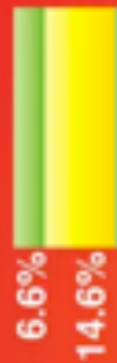

Native (approx. 430 million)

Non-native (approx 950 million)

Non-speakers (approx 5.1 billion)

1 in 5 of the world's population speak English as either a native, second of foreign language.

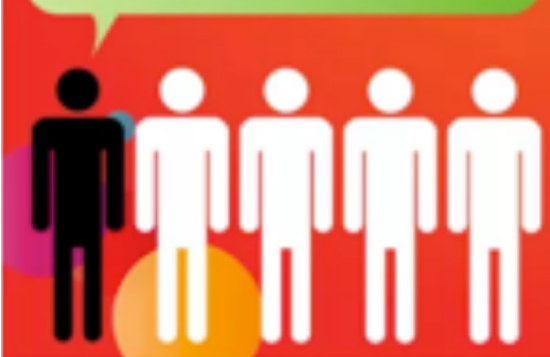

Non-native speakers outnumber native speakers of English by more than two to one.
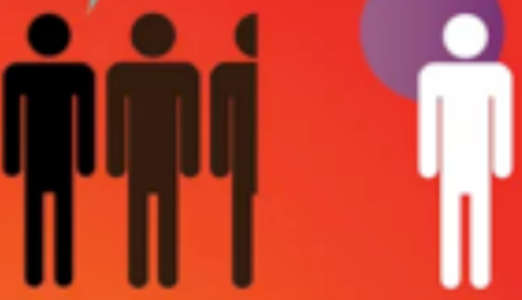

Non-native

Native

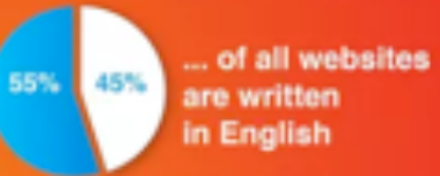

\section{India has over}

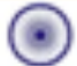

\section{$125,000,000$}

\section{ESL speakers}

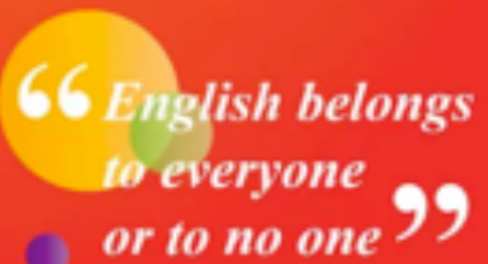

Fonte: LDLI-02, v. 1, p. 21.

Figura 13 - Infográfico sobre o inglês como língua mundial 

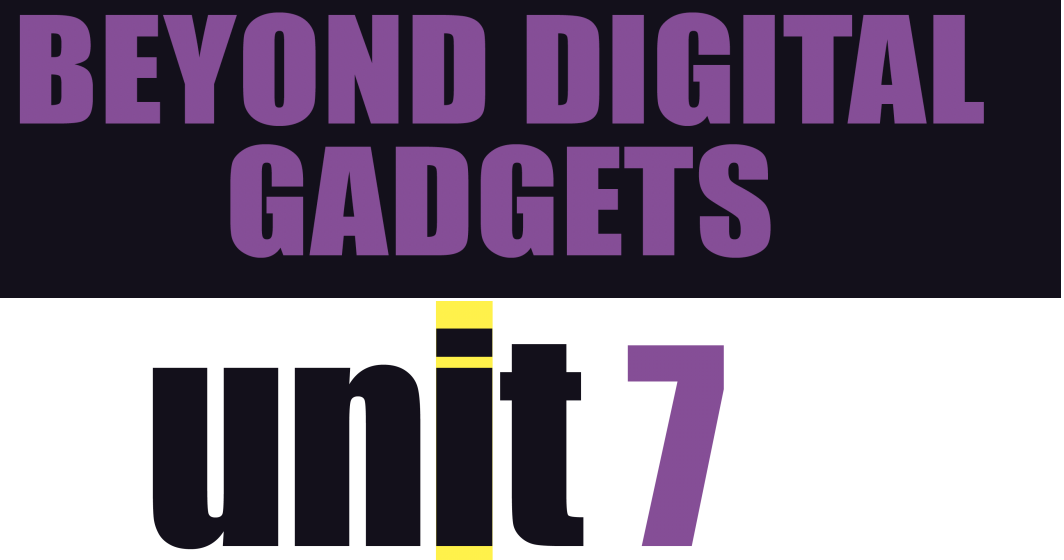

Fonte: LDLI-01, v. 1, p. 124-125.

Figura 14 - Título de unidade no LDLI-01

\section{Studying with Technology}

Fonte: LDLI-02, v. 1, p. 15.

Figura 15 - Título de unidade no LDLI-02

O layout do tipo complementar com imagens e verbiagem em espaços distintos é o mais comum nas duas coleções do corpus e, por questões do escopo deste artigo, nossa análise vai se ater à abertura das unidades e à seção de escrita. Todas as páginas de abertura de ambas as coleções recebem uma diagramação interpolada na direção horizontal, na vertical ou em ambas, onde imagens e verbiagens alternam-se para veicular seus propósitos de comunicação, o de informar sobre o tema e sobre os objetivos de aprendizagem da unidade. 
Percebe-se que as equipes editoriais das duas coleções tiveram a intenção de incluir os aspectos de funcionalidade e de estética verbo-visual para favorecer a legibilidade, assim como para captar a atenção e desenvolver a motivação dos alunos para o que está por vir, em cada uma das unidade das coleções. Como mostram os exemplos a seguir, o LDLI-01 explora o uso da interpolação horizontal, se considerarmos o conjunto das duas páginas de abertura, e também a interpolação vertical, quando cada página é analisada individualmente (Figura 16). Na página à esquerda, temos a sequência imagem e verbiagem, enquanto, à direita, podemos observar, no primeiro bloco da diagramação, uma interpolação horizontal (verbiagem-imagem), complementada na vertical pela interpolação vertical (imagem que se refere à indicação do título da unidade, seguida por um conjunto de imagem e verbiagem que são as perguntas sobre o tema e as imagens nas páginas de abertura). O último bloco assemelha-se ao primeiro por ser interpolado na horizontal, mas com uma sequência diferente: à esquerda, encontra-se a verbiagem, e à direita, a imagem, delimitadas pela margem superior e inferior respectivamente.
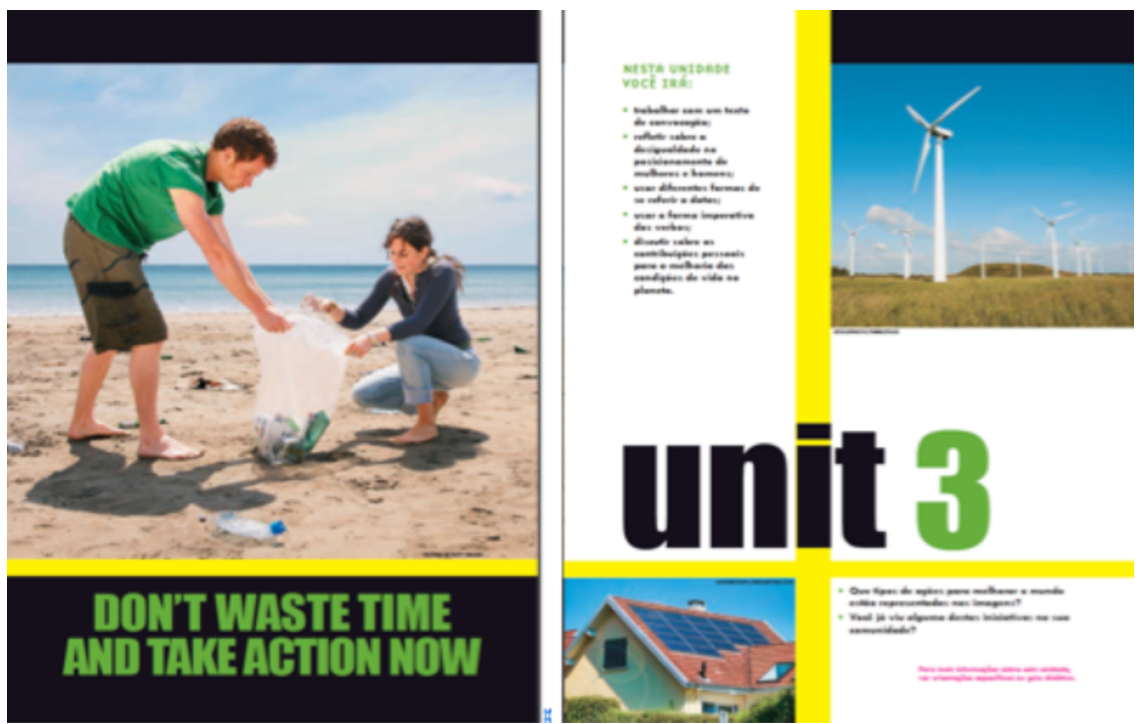

Fonte: LDLI-01, v. 1, p. 48-49.

Figura 16 - Páginas de abertura de unidade no LDLI-01 
No LDLI-02, por outro lado, prevalece, em todas as unidades, o uso da diagramação interpolativa vertical, na sequência verbiagem relativa às perguntas sobre as imagens que representam o tema, imagens que o representam e, de novo, a verbiagem que apresenta os objetivos de aprendizagem.

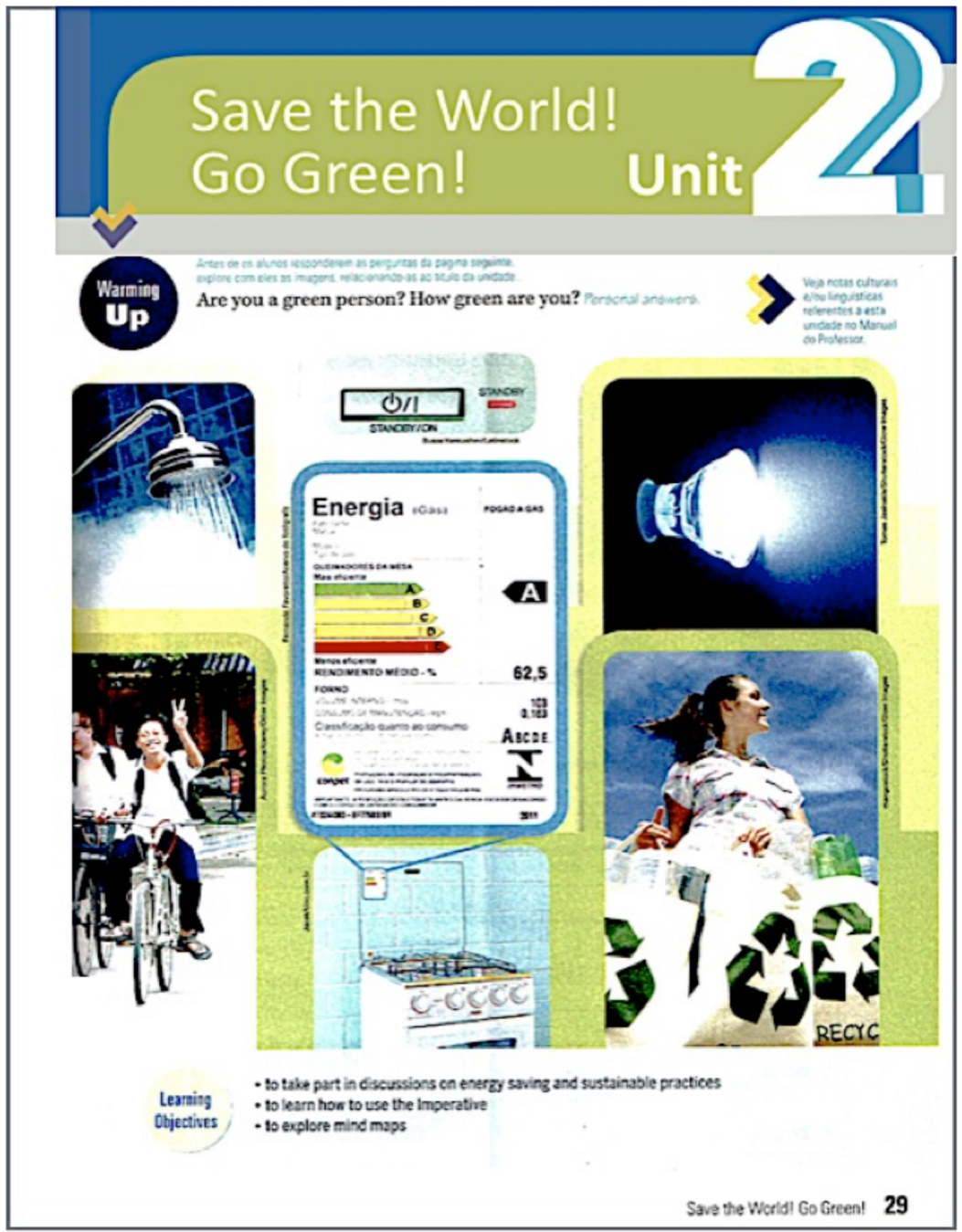

Fonte: LDLI-02, v. 1, p. 29.

Figura 17 - Página de abertura de unidade no LDLI-02 
É possível afirmar que ambos os livros valorizam o espaço verbovisual em suas páginas de abertura, com o uso de imagens estreitamente relacionadas ao tema da unidade e com utilização da verbiagem para as perguntas sobre as imagens presentes na(s) página(s), a fim de informar os objetivos de aprendizagem e proporcionar discussões e reflexões na sala de aula. Os títulos e a indicação dos números de suas unidades recebem maior saliência pelo uso de recursos tipográficos, pela rima visual e pelo uso de cores semelhantes. Nota-se que, no LDLI-01, há uma leve predominância ou valorização das imagens e do seu relacionamento com a verbiagem, o que pode, talvez, envolver os alunos às ações de aprendizagem de uma maneira mais efetiva.

A seção destinada à produção escrita de ambos os livros apresenta também uma diagramação interpolada vertical, usualmente na seguinte sequência: verbiagem, imagem(ns) e verbiagem. Ambas começam com o título da seção, Put it in writing e Writing (LDLI-01 e LDLI-02, respectivamente), e trabalham com a visão de escrita como processo colaborativo. $\mathrm{Na}$ verbiagem estão também presentes as orientações tanto sobre o que escrever e sobre o gênero que será composto. No LDLI-01, há ainda os critérios com os quais os alunos podem avaliar a qualidade de suas composições escritas, seus layouts e se atendem ao público-alvo ao qual se destina e, no LDLI-02, há informações gramaticais enquadradas em um quadro colocado sempre à direita da página e com respeito à margem. As seções de writing de todos os três volumes da coleção 02 recebem destaque tipográfico por meio do uso da caixa alta para o título e subtítulos e pelo uso da cor rosa, em tonalidades diferentes. São em número de oito, uma por unidade. As da coleção 01, entretanto, usam as cores escolhidas para as diversas unidades. Por exemplo, na Unidade 2, o destaque é em laranja; na 4 , em verde; na 6 , em azul e na 8 , em roxo. São no total quatro, sempre nas unidades pares. 


\section{Put lt in Writing}

Plan your writing.

What to write: An informative flyer.

Purpose: To call people's attention to a specific problem in your neighborhood.

Audience: The community where you live.

Brainstorm some of the problems you face in your neighborhood and choose one. Make a chart in your notebook to write your notes. Look at the example below.

\begin{tabular}{|l|l|l|}
\hline \multicolumn{1}{|c|}{ Prohlem } & \multicolumn{1}{c}{ Reasons } \\
\hline trash on the streets & $\begin{array}{l}\text { it causes floods } \\
\text { it's not good for our health }\end{array}$ & use trash bins \\
\hline
\end{tabular}

Study the flyer made for the example given above. Complete with the information from the chart. Respostas pessoais. Se julgar conveniente, sugerir

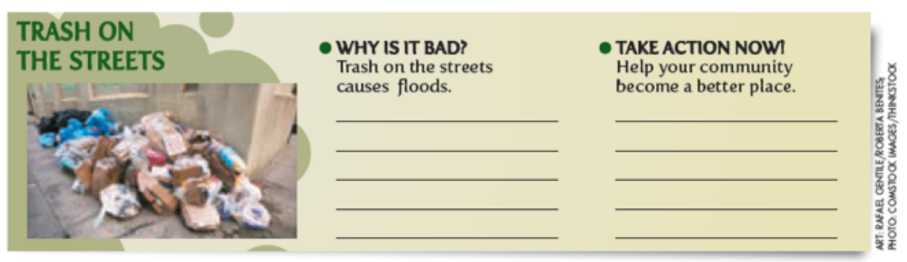

Fonte: LDLI-01, v. 1, p. 76.

Figura 18a - Seção sobre escrita

Flyers are announcements or advertisement printed on a piece of paper and distributed to people or posted in public places.
Major characteristics:
- interesting and attractive layout; - effective position of the information to facilitate reading;
- use of images, charts, or illustrations; - text is short, direct, and concise.

Design and write your flyer. Remember to use images and titles. Make it attractive and interesting. Use the checklist below to revise your text.

1 It respects the characteristics of the genre.

2 It meets my writing objectives.

3 The language is appropriate to my audience.

4 The text uses good grammar and punctuation.

- If you checked no in any topic above, rewrite your flyer.

Publish your flyer. Se os recursos permitirem, pedir aos alunos que reproduzam cópias dos flyers confeccionados para serem distribuidas na escola. Outra sugestäo é afixar os flyers nos quadros de avisos da escola.

Fonte: LDLI-01, v. 1, p. 76.

Figura 18b - Seção sobre escrita 
In this unit you have read descriptions of paintings on pages 69 and 70 . These descriptions can be found in museum sites, art review magazines, blogs and other sites about art etc. Notice they describe some important elements in the picture, such as the central figure, the background and the colors.

\section{WRITING GUIDELINES}

1. Now it's your turn to write a description of a picture (painting, photo or drawing) to share your personal views on it. You and your colleagues may choose to focus on an artist, a theme or an art movement. artist, a theme or an art movernent.

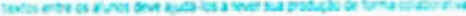

\section{STEP BY STEP}

1 Select a paintine photograph cr drawing.

2. Start your description by saying the name of the picture and the artist.

3. Mention some of the important elements in the picture (central figure. colors, background. movement etc)
4. Illustrate it with the picture of the painting. photograph or drasing you described.

5. Add a trite (the name of the picture).

6. Exchange descriptions with a classmate and ciscuss both teats.

2. Make the nocessary corrections.

8. Write the tinal versicn of the description

\section{Useit! \\ in your devenctoon you can nduce expressions wuch as \\ - is cene of the mont wril ktown pieces ef artwouk ia kistory. \\ What is so cripging about the image is that \\ This puirting is a attempt te. \\ The most inpoetant figix is. \\ Emptasa is put visudily ca the.}

Fonte: LDLI-02, v. 1, p. 75.

Figura 19 - Seção sobre escrita 


\section{Enquadramento: o delimitado e o não delimitado}

A diagramação dos três volumes dos dois livros sob análise é bem padronizada e cada uma adota praticamente os mesmos recursos para a composição verbo-visual das seções de suas unidades. Em termos do enquadramento, ambas apresentam os dois tipos da seguinte maneira: praticamente todas as páginas são delimitadas, sendo suas margens bem definidas. As exceções são as páginas de abertura do LDLI-01 e as páginas de Reading, reading for general and detailed comprehension do LDLI-02, que se expandem em páginas duplas.

O enquadramento delimitado, com ou sem moldura, é o mais comum ao longo das unidades das duas coleções. Recebem esse tipo de enquadramento: os textos para a compreensão escrita, as imagens que aparecem no corpo das unidades, as explicações gramaticais, algumas das atividades de produção oral e de compreensão oral, entre outras composições espaciais. Os objetivos parecem ser o de destacar informações, aumentar a legibilidade da página e concorrer para uma composição verbo-visual mais agradável para os leitores.

\section{Grupo focal central}

Os grupos focais centrípetos, na vertical ou na horizontal, são os mais comuns nas duas coleções, seguindo, assim, as orientações do layout polarizado ou interpolado que é o mais frequentemente utilizado pela equipe editorial de cada uma das obras. Os exemplos dos grupos focais para nossa análise serão retirados das seções de pré-leitura do volume 1, Have your say, que é seguida de uma ou duas perguntas sobre o texto a ser lido, em outra página, e Before Reading, que é antecedida por outras atividades de compreensão relacionadas ao tema no LDLI-01 e no LDLI-02, respectivamente.

A seção Have your say das unidades English everywhere, How can your change the world? e Beyond digital gadgets, no volume 1 do LDLI-01, encontra-se organizada em duas páginas e todas as três seções contêm mais de um grupo focal. Na página à esquerda da unidade English everywhere, por exemplo, há 
um mapa do mundo no qual os vários países de língua inglesa são destacados com números sobre a cor roxa. Ele se encontra no centro e ocupa um grande espaço no layout. A verbiagem (atividades 1 e 2 sobre esses países) encontra-se acima e abaixo desse foco central e é delimitada pelas margens superior e inferior. Na página à direita, a imagem desloca-se do centro para ser colocada mais acima, quase no topo da página, e é antecedida e seguida de verbiagem. A atividade 6 dessa página está relacionada à imagem central da página anterior, supostamente numa tentativa de valorizar a intepretação de espaços visuais relacionados a informações verbais. Em How can you change the world, a página à direita contém apenas a verbiagem, diagramada de acordo com o design estabelecido pelo editorial. À esquerda, porém, o olhar do usuário é guiado para a metade inferior da página, em direção a um mapa de 2011 sobre o Índice de Desenvolvimento Humano de vários países, incluindo o Brasil. Ao lado dele, uma legenda e uma bússola. Há verbiagem acima e abaixo dele, delimitada pela margens superior e inferior, respectivamente. A unidade 7 apresenta dois grupos focais em sua seção Have your say, um à esquerda, que ocupa quase toda a página, e outro à direita, na parte inferior do espaço composicional, formado por quatro imagens, seguidas de linhas para as respostas por escrito pelos alunos. Todas as ilustrações foram retiradas de banco de imagens. Em todas as unidades do livro, a seção Have your say é seguida por Reading beyond the words, que sempre contém uma ou duas perguntas relacionadas à formação de hipóteses pelos alunos sobre o conteúdo dos textos que serão lidos. 


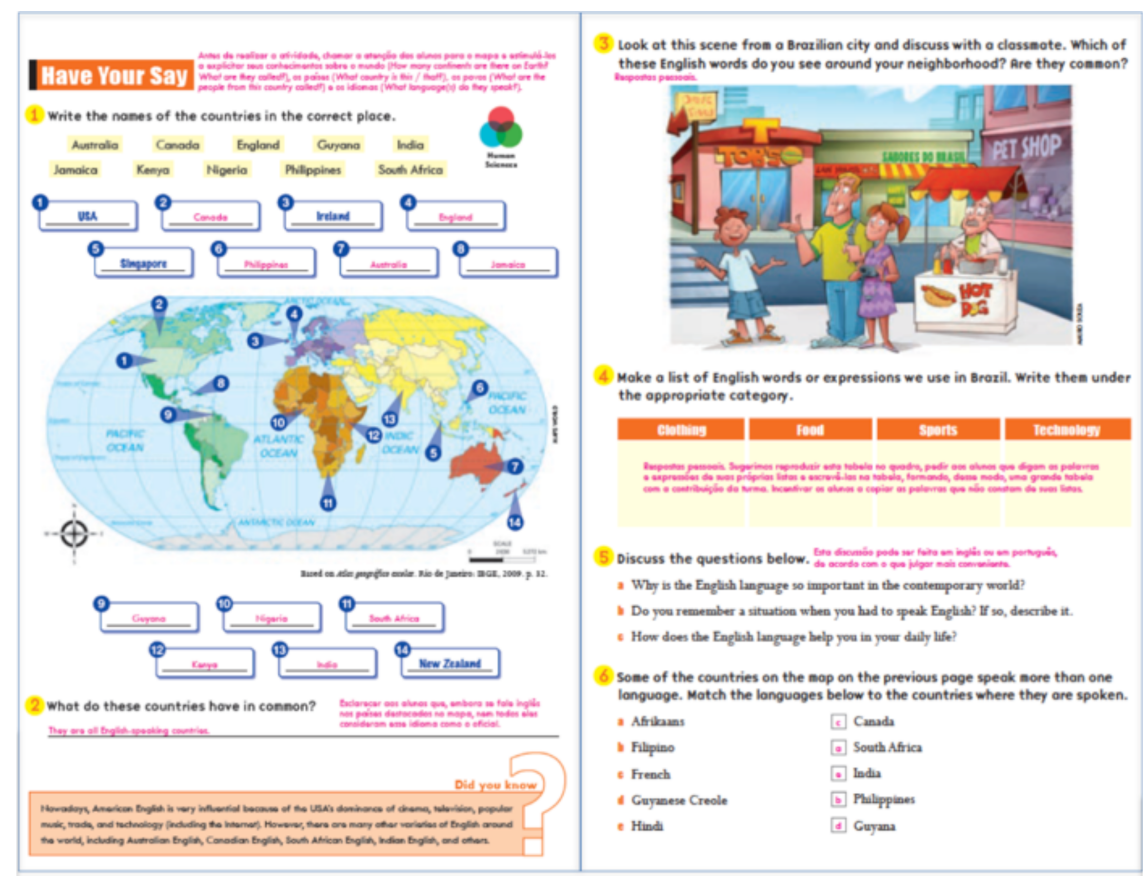

Fonte: LDLI-01, v. 1, p. 12-13.

Figura 20 - Ativação de conhecimento anterior

A seção Have your say da unidade 2 do LDLI-01, Brazil: our people, our country, contém dois grupos focais, interpolados por verbiagem, acima e abaixo deles. O primeiro, na metade superior da página, é uma representação de um verbete de dicionário que contém, ao seu lado direito, a definição do conceito "estereótipo". O outro grupo é formado por duas imagens adjacentes na direção horizontal, uma do lado da outra, que ilustram estereótipos dos povos americanos e britânicos, respectivamente. A unidade 3 do mesmo livro, Don't waste time and take action now, contém um foco central que ocupa quase toda a página, cuja organização espacial se destaca por ser a única desse tipo em toda a coleção. Ele é formado no sentido horizontal, na sequência imagem, verbiagem, imagem. Acima e abaixo dele, a verbiagem que inclui as atividades escritas sobre o tema. A atividade sobre esse grupo 
focal é uma tentativa das autoras de integrar o verbo-visual na compreensão escrita pelos alunos. Ainda no LDLI-01, na unidade 5, How intelligent are you, o grupo focal ocupa a metade da parte superior da página. Trata-se de um diagrama com as múltiplas inteligências que o representam tanto no modo visual quanto no verbal com representações imagéticas para cada uma e seus nomes incluídos, adjacentes às suas imagens. A outra metade da página contém apenas verbiagem, mas é uma atividade que incentiva o relacionamento do verbal (definições de cada inteligência) ao diagrama que se configura como o foco no layout.

A unidade 6 do LDLI-01, Study Skills, contém dois grupos focais, um na parte superior e o outro, na parte inferior da página, delimitados acima e abaixo pelas margens. Entre eles, a verbiagem, ao centro, que contém as atividades sobre o tema da unidade. A seção Have your say da unidade 8, Constant Connectiveness, difere de todas as outras por conter apenas verbiagem, que foi diagramada conforme o design estabelecido para a coleção.

As unidades 1 e 2 do LDLI-02, Studying with technology e Save the world! Go green!, (p. 17 e 31, respectivamente), recebem um layout interpolado, sendo as imagens ilustrativas dos respectivos temas, ocupando o centro das páginas, com verbiagem acima e abaixo delas. Percebe-se que a imagem da unidade 1 foi retirada de um banco de imagens e a da unidade 2 é uma ilustração produzida pelo próprio editorial. As páginas à esquerda, com atividades sobre o tema, recebem destaques diferentes para os grupos focais. Na unidade 1 , verbiagens e imagens se alternam na direção vertical. $\mathrm{Na} 2$, a composição espacial agrupa imagens na direção horizontal, adjacentes à verbiagem que se encontra à esquerda. 


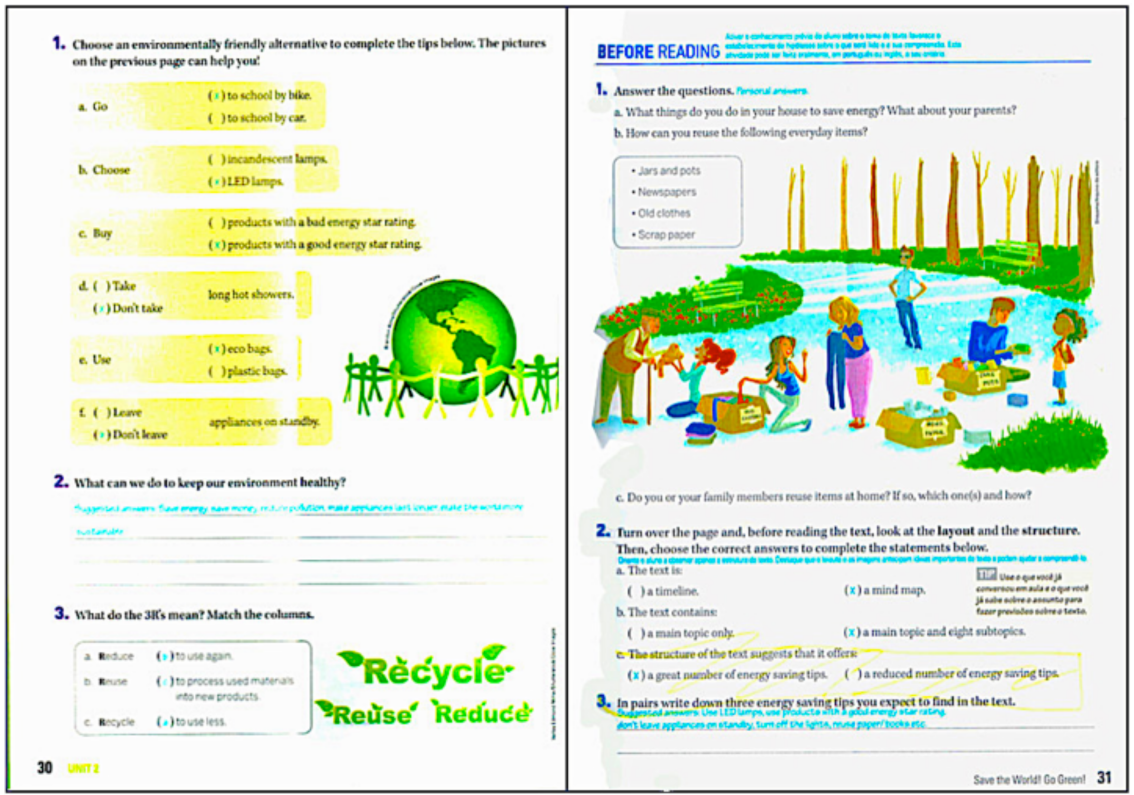

Fonte: LDLI-02, v. 1, p. 30-31.

Figura 21 - Ativação de conhecimento anterior

Na unidade 3 do LDLI-02, Traveling around Brazil, o grupo focal, para o qual a atenção do usuário é direcionada, foi disposto na página à esquerda do texto de leitura, posicionando-se ao lado dele. Tal composição difere das utilizadas nas outras unidades, nas quais o estudo relativo à seção Before reading sempre começa na página ímpar, após a discussão sobre o tema cujas atividades encontram-se na página par. Em sua composição foi utilizado o layout integrado com a verbiagem sobre imagens que correspondem à atividade 1 , na página 50, com perguntas para a ativação de conhecimento anterior do aluno sobre o tema da unidade, ilustradas com pontos turísticos brasileiros. As atividades 2 e 3, a seguir, na página 51, contêm apenas verbiagem e seguem a diagramação implementada na maioria das páginas da obra. A página 50, à esquerda, tem o seu grupo focal na horizontal, posicionado quase no topo, interpolado por verbiagem acima e abaixo dele. $\mathrm{Na}$ unidade 4, intitulada Feel the image, feel the feeling, há apenas verbiagem na seção Before 
reading, seguindo as orientações de projeto de diagramação. O grupo focal da página 64, à esquerda, encontra-se na parte inferior da composição, sendo que a verbiagem está acima dele, ocupando um espaço maior na organização espacial da página.

As seções Before reading da unidade 5 do LDLI-02, Old heroes - new heroes, e a da 7, Have fun and get fit, apresentam grupos focais em posições semelhantes. Ambas contêm, na parte superior da página, composições espaciais que complementam as informações verbo-visuais, adjacentes umas às outras, na direção horizontal. A verbiagem completa o resto do espaço composicional. À esquerda, nas páginas 84 e 118, os grupos focais encontramse na parte inferior da composição, sendo delimitadas pelas margens. Acima deles, foi diagramada a verbiagem referente às atividades sobre os temas de cada uma das unidades, seguindo o padrão estabelecido para o design das coleção. Embora semelhantes na posição ocupada no layout, o grupo focal da página 118 apresenta verbiagem (perguntas sobre as opiniões dos alunos a respeito do tema da unidade) incluída sobre as imagens de dois adolescentes em frente a uma tela de televisão, representando sua ação de jogar video game juntos.

A página 99 da unidade 6 no do LDLI-02, Inventions and discoveries, foi diagramada com dois grupos focais na parte inferior, um referente a um mapa mental, que deve ser preenchido pelos alunos, e o outro a um quadro com fundo escuro sobre o qual há a representação de uma lâmpada incandescente e algumas equações numéricas, para darem a ideia de descobertas e invenções, tema da unidade. É bem provável que tenha sido retirada de um banco de imagens. A página 98, à esquerda, possui um layout bem diferente dos demais do volume 1. É composto por três grupos focais, o primeiro com a parte verbal sobre o cientista Einstein, adjacente à sua foto; o segundo é um quadro retangular com fundo verde que recebe sua biografia curta; e o terceiro, sua timeline, que deve ser preenchida pelos alunos com base em conhecimento anterior.

A seção Before Reading da unidade 8 do do LDLI-02, Express yourself through words, contém um grupo focal que consiste de verbiagem sobre o escritor Langston Hughes e sua foto, adjacentes um ao outro. Esse espaço composicional é interpolado por verbiagem acima e abaixo, delimitada pelas margens inferior e superior da página. À esquerda, podemos perceber a 
seguinte sequência no layout: verbiagem, grupo focal central, representado por um mapa mental seguido de um outro grupo focal, formado por verbiagem à esquerda e imagem, à direita, uma do lado da outra, delimitadas pela margem inferior da página.

As análises aqui empreendidas sugerem que os elementos para uma ADMSF apresentados por Painter, Martin e Unsworth (2013) apresentam-se extremamente produtivos para uma compreensão dos LDLI como objetos multifacetados, sendo que os elementos analisados permitem tanto explorações mais amplas para os multiletramentos dos alunos quanto para a inserção de elementos multimodais na formação do professor de línguas, como discutimos a seguir.

\section{A Composição Verbo-Visual dos LDLI e a Formação do Professor de Inglês}

Embora nossa análise revele que tanto o LDLI-01 quanto o LDLI-02 apresentam diagramações adequadas que evidenciam os aspectos de destaque para facilitar e promover a aprendizagem de inglês, elas são de responsabilidade das respectivas equipes editoriais. Os autores não participam desse trabalho importante na expressão de significados em coleções didáticas, podendo entendê-lo e analisá-lo, mas não se envolver com ele, durante o processo de sua implementação. É bem possível que muitos dos professores de inglês da escola pública que usam essas duas obras não percebam a relevância dos recursos e efeitos da diagramação para a construção de conhecimentos pelos alunos. Nenhum dos dois manuais do professor dessas coleções traz referências à relevância da composição verbo-visual para apoiar o trabalho pedagógico que é feito em sala de aula, no Ensino Médio, e aí reside um campo profícuo a ser explorado no campo de formação de professores de línguas.

Além disso, reconhecemos, por meio da análise empreendida, a ubiquidade das inter-relações verbo-visuais na composição espacial dos dois livros didáticos de inglês e a necessidade do professor de explorá-las, com mais profundidade, em suas práticas pedagógicas. Em nossa posição, uma estratégia de ensino que valorize a metafunção textual pode não só promover a aprendizagem de inglês, mas também ser uma ponte para o entendimento 
e a compreensão dos alunos dos aspectos das outras duas metafunções, a ideacional e a interpessoal, favorecendo o uso da língua inglesa em práticas sociais de comunicação oral e escrita por eles e ainda sua formação não somente para o mundo multissemiotizado que o rodeia, mas também para a cidadania.

Por reconhecermos esses aspectos e por percebermos que os dois livros analisados tratam da relação verbo-visual de maneira abrangente e superficial, recomendamos que os cursos de formação do professor de inglês, na fase inicial ou na continuada, incluam referências sobre a multimodalidade, o espaço composicional e as diversas maneiras de combinação da verbiagem e do visual. Com isso, o professor pode melhor compreender o discurso multimodal e suas características para desenvolver os letramentos (KALANTZIS; COPE, 2012) dos alunos para ler, escrever, ouvir e falar, além de prepará-los para o respeito às diversidades frente às interações colaborativas frequentes da era digital. Mesmo essas duas coleções analisadas ainda precisam ser revisitadas, tendo em vista a ADMSF, para melhor se adequarem às necessidades dos alunos do Ensino Médio para o enfrentamento dos desafios escolares e profissionais que têm pela frente.

\section{Considerações Finais}

Este texto teve como objetivo discutir as possibilidades do aspecto verbo-visual dos LDLI na conjunção entre verbiagens e imagens e como elas se configuram. Partimos do princípio, indicado por Bunzen (2008), de considerar o livro didático como um objeto complexo e multifacetado e, associado a isso, trouxemos elementos da ADMSF que consideram a metafunção textual e os modos como imagem/verbiagem podem estar relacionadas no LDLI.

Inseridos na perspectiva de uma ADMSF, apresentamos os sistemas de Integração Intermodal, Enquadramento e Foco, conforme propostos por Painter, Martin e Unsworth (2013) e como estes sistemas apresentam-se caracterizados nos dois LDLI analisados, como forma de verificar como a integração entre verbiagens e imagens tem sido configurada nos livros aprovados pelo PNLD para língua inglesa. 
A ADMSF possibilita análises mais abrangentes pelo fato de considerar aspectos linguísticos e semióticos presentes nos textos, permitindo que se vislumbre o letramento multimodal como uma possibilidade de abordagem do livro didático em sala de aula no ensino de língua inglesa, assim como na formação do professor de inglês e como os elementos podem ser explorados para possibilidades de letramentos críticos mais sensíveis às práticas e aos contextos da educação básica brasileira.

\section{Referências}

ABIO, G.; DIAS, R. Una mirada preliminar a la visualidad de los libros brasileños para enseñanza de ELE aprobados por el PNLD 2015. MarcoELE: Revista de Didactica, v. 22, p. 1-27, 2016.

BRASIL. Ministério da Educação. Fundo Nacional de Desenvolvimento da Educação. Guias de livros didáticos/PNLD 2012: Língua Estrangeira Moderna. Brasília: Ministério da Educação, Secretaria de Educação Básica, 2011.

BRASIL. Ministério da Educação. Fundo Nacional de Desenvolvimento da Educação. Guias de livros didáticos PNLD 2015. Língua Estrangeira Moderna - Inglês e Espanhol. Brasília: MEC; SEB; FNDE, 2014.

BUNZEN, C. S. Livro didático de língua portuguesa: um gênero do discurso. 2005. Dissertação (Mestrado em Linguística Aplicada) - Universidade Estadual de Campinas, Campinas.

BUNZEN, C. S. O livro didático de português como um gênero do discurso: implicações teóricas e metodológicas. In: SIMPÓSIO SOBRE O LIVRO DIDÁTICO DE LÍNGUA MATERNA E ESTRANGEIRA SILID, 1., 2008, Rio de Janeiro. Anais do I SILID. Rio de Janeiro: Edições Entrelugar, 2008. p. 1-16. Disponível em: <http://bit.ly/2BvK53w>. Acesso em: 26 maio 2016.

CORACINI, M. (Org.). Interpretação, autoria e legitimação do livro didático: língua materna e língua estrangeira. Campinas: Pontes, 1999. 
COSTA VAL, M. da G.; MARCUSCHI, B. (Orgs.). Livros didáticos de língua portuguesa: letramento e cidadania. Belo Horizonte: CEALE; Autêntica, 2005.

DIAS, R.; CRISTOVÃO, V. L. L. (Org.). O livro didático de língua estrangeira: múltiplas perspectivas. Campinas: Mercado de Letras, 2009.

DIAS, R.; JUCÁ, L.; FARIA, R. High Up. Cotia: Macmillan, 2013.

GUALBERTO, C. L. Multimodalidade em Livros Didáticos de Lingua Portuguesa: uma análise a partir da semiótica social e da gramática do design visual. 2016. Tese (Doutorado em Estudos Linguísticos) Universidade Federal de Minas Gerais, Belo Horizonte.

HALLIDAY, M. A. K. Language as a social semiotic: the social interpretation of language and meaning. Ann Arbor, MI: University of Michigan, 1978.

HALLIDAY, M. A. K. An introduction to Functional Grammar. London: Edward Arnold, 1985.

JEWITT, C. (Ed.). Handbook of multimodal analysis. London: Routledge, 2009.

KALANTZIS, M.; COPE, B. Literacies. New York; London: Cambridge, 2012.

KRESS, G.; VAN LEEUWEN, T. Reading images: the grammar of visual design. London: Routledge, 1996.

KRESS, G.; VAN LEEUWEN, T. Reading images: the grammar of visual design. 2. ed. London: Routledge, 2006.

O'HALLORAN, K. Multimodal discourse analysis: systemic-functional perspectives. London: Continuum, 2004.

PAINTER, C.; MARTIN, J. R.; UNSWORTH, L. Reading visual narratives: image analysis of children's picture books. Sheffiled, UK; Bristol, CT, USA: Equinox Publishing, 2013. 
PREDEBON, N. R. C. Do entretenimento à crítica: letramento multimodal crítico no livro didático de inglês com base em gêneros dos quadrinhos. 2015. Tese (Doutorado em Letras) - Universidade Federal de Santa Maria, Santa Maria.

PONTIFÍCIA UNIVERSIDADE CATÓLICA DO RIO DE JANEIRO - PUC-Rio. V SILID / IV SIMAR. 2015. Disponível em: $<$ http://bit.ly/2iRYFes>. Acesso em: 30 maio 2016.

ROJO, R.; BATISTA, A. (Org.) Livro didático de língua portuguesa, letramento e cultura da escrita. Campinas: Mercado de Letras, 2003.

SALBEGO, N.; HEBERLE, V. M.; BALEN, M. G. S. S. A visual analysis of English textbooks: Multimodal scaffolded learning. Calidoscópio, v. 13, n. 1, p. 5-13, 2015.

SILVA, R. C. O livro didático de inglês como um gênero discursivo multimodal promotor de letramentos múltiplos. In: HEMAIS, B. J. W. (Org.). Gêneros discursivos e multimodalidade: desafios, reflexões e propostas no ensino de inglês. Campinas: Pontes, 2015. p. 35-62.

TAVARES, K.; FRANCO, C. Way to go! São Paulo: Ática, 2014.

TÍLIO, R. Enfoque em leitura na aula de inglês: PCN e letramento crítico. In: SILVA, K.; ARAÚJO, J. (Org.). Letramentos, discursos midiáticos e identidades: novas perspectivas. Campinas: Pontes, 2015. p. 257-287.

UNIVERSIDADE DE SÃO PAULO - USP. Departamento de Letras Clássicas e Vernáculas. Objetivos do I Seminário de Pesquisa de Livros Didáticos de Lingua Portuguesa. 2012.

XAVIER, J. P. Letramento visual crítico: leitura, interpretação e apropriação das imagens nos livros didáticos. 2015. Dissertação (Mestrado em Estudos Linguísticos) -Universidade Federal de Minas Gerais, Belo Horizonte.

Recebido em: 21/12/2016

Aceito em: 17/04/2017 